\title{
Solutions for ultra-high speed optical wavelength conversion and clock recovery
}

Oxenløwe, Leif Katsuo; Galili, Michael; Mulvad, Hans Christian Hansen; Clausen, Anders; Zibar, Darko; Jeppesen, Palle

\section{Published in:}

Proceedings of International Conference on Transparent Optical Networks 2006

Link to article, DOI:

10.1109/ICTON.2006.248356

Publication date:

2006

Document Version

Publisher's PDF, also known as Version of record

Link back to DTU Orbit

Citation (APA):

Oxenløwe, L. K., Galili, M., Mulvad, H. C. H., Clausen, A., Zibar, D., \& Jeppesen, P. (2006). Solutions for ultrahigh speed optical wavelength conversion and clock recovery. In Proceedings of International Conference on Transparent Optical Networks 2006 (Vol. 2, pp. Tu.D2.3). IEEE. https://doi.org/10.1109/ICTON.2006.248356

\section{General rights}

Copyright and moral rights for the publications made accessible in the public portal are retained by the authors and/or other copyright owners and it is a condition of accessing publications that users recognise and abide by the legal requirements associated with these rights.

- Users may download and print one copy of any publication from the public portal for the purpose of private study or research.

- You may not further distribute the material or use it for any profit-making activity or commercial gain

- You may freely distribute the URL identifying the publication in the public portal 


\title{
Solutions for Ultra-High Speed Optical Wavelength Conversion and Clock Recovery
}

\author{
Leif K. Oxenløwe, Michael Galili, Hans Christian Hansen Mulvad, Anders T. Clausen, Darko Zibar \\ and Palle Jeppesen \\ COM-DTU, Department of Communications, Optics and Materials at the Technical University of Denmark \\ DTU building 345V, DK 2800 Kongens Lyngby, Denmark \\ e-mail:lo@com.dtu.dk.
}

\begin{abstract}
This paper reports on our recent advances in ultra-fast optical communications relying on ultra-short pulses densely stacked in ultra-high bit rate serial data signals at a single wavelength. The paper describes details in solutions for the network functionalities of wavelength conversion and clock recovery at bit rates up to $320 \mathrm{~Gb} / \mathrm{s}$.
\end{abstract}

Index Terms-OTDM, clock recovery, demultiplexing, regeneration, wavelength conversion.

\section{INTRODUCTION}

Despite the post-bubble set-back, there is still a growing pursuit of increasing the single channel bit rate, either by electronic means, reaching $100 \mathrm{~Gb} / \mathrm{s} \mathrm{[1],} \mathrm{(currently} \mathrm{being}$ challenged in research labs around the world) or by optical means, reaching $640 \mathrm{~Gb} / \mathrm{s}$ by pure intensity modulation [2][5], $1.28 \mathrm{~Tb} / \mathrm{s}$ using intensity modulation and polarisation multiplexing [6], and very recently $2.56 \mathrm{~Tb} / \mathrm{s}$ using multilevel phase modulation and polarisation multiplexing [7].

The above achievements were demonstrated as point-topoint transmission experiments. The next step is to investigate how optical networking functionalities may be implemented at such high speeds. In that context, this paper will discuss advances in our labs as well as state the general status in the areas of all-optical wavelength conversion and regeneration at high speed as well as clock recovery.

To generate and further characterise high bit rate signals, one may employ an optical time division multiplexed (OTDM) system. A basic OTDM system is sketched in figure 1. To obtain the high bit rate, optical time interleaving is performed on pulses derived from ideally a single pulse source running at a base rate B. In a multiplexer (MUX), the original pulse train is split into $\mathrm{N}$ arms, corresponding to individual data channels. Each data channel may be individually data modulated (laboratory solutions often include a single modulator before the MUX), and each channel is delayed appropriately to allow for correct bit interleaving, forming a string of densely packed data pulses at the aggregate bit rate $\mathrm{N} \times \mathrm{B}$. The multiplexed data is launched over a span of transmission fibre. During transmission, the signal may be impaired by group velocity dispersion (GVD), higher order dispersion, polarisation mode dispersion (PMD), non-linear effects and loss. All needs to be very carefully compensated for and some sort of passive

Authors are with COM-DTU, Department of Communications, Optics and Materials at the Technical University of Denmark, DTU building 345V, DK2800 Kongens Lyngby, Denmark, lo@com.dtu.dk.

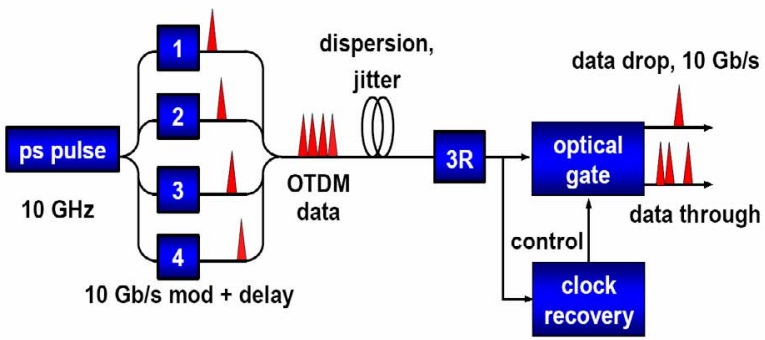

Fig. 1. A basic OTDM system. Narrow pulses are bit interleaved. Transmission impairments must be compensated for very carefully. Clock recovery with a very high timing resolution is necessary and a demultiplexer with narrow switching windows is required to demodulate the signal.

or active regeneration at the line rate may be advantageous. After transmission, at some network node, the node will need to be synchronised to the incoming data, so that it may be processed, e.g. dropping a channel (demultiplexing) in an add/drop multiplexer. The network functionalities regeneration utilising wavelength conversion and clock recovery, will be the topic of this paper. As narrow pulses form the foundation of these systems, general rules for these will also be given.

\section{PUlse SOURCES}

1) Pulse requirements: Narrow high quality pulses are the essential pre-requisite for an OTDM system. The requirements to short pulse sources have been computed taking into account interference from pulse tails of neighbouring channels and the requirements to pulse tail extinction ratio (PTER) are stated in table I, where the requirement to the pulse width is that the full width half maximum (FWHM) should be $0.4 \times$ the time slot, i.c. $2.5 \mathrm{ps}$ for a $160 \mathrm{~Gb} / \mathrm{s}$ signal [8].

\begin{tabular}{|c|c|}
\hline bit rate $[\mathrm{Gb} / \mathrm{s}]$ & min PTER $[\mathrm{dB}]$ \\
\hline & \\
$4 \times 40$ & 27 \\
$8 \times 40$ & 33 \\
$16 \times 40$ & 37 \\
$32 \times 40$ & 41 \\
\hline
\end{tabular}

TABLE I

REQUIREMENTS TO PULSE TAIL EXTINCTION RATIO (PTER) AT VARIOUS BIT RATES FOR A FWHM OF $0.4 \times$ TIME SLOT

2) Available pulse sources: A number of different pulse sources generating narrow transform limited $(\mathrm{TF})$ pulses adequate for OTDM systems have been developed and refined 


\begin{tabular}{|c|c|c|}
\hline pulse source & pros & cons \\
\hline ERGO PGL & $\begin{array}{c}\text { TF } \sim 1 \mathrm{ps}, \\
\text { simple, small, } \\
\text { wavelength tuneable } \\
320 / 640 \mathrm{~Gb} / \mathrm{s} \text { demo }[9]\end{array}$ & $\begin{array}{l}\text { small rep rate tuning, } \\
\text { trailing pulses due to AR }\end{array}$ \\
\hline TMLL & $\begin{array}{c}\text { TF } \sim 1 \mathrm{ps}, \text { small, } \\
\text { tuneable } \lambda, \text { f, FWHM } \\
320 / 640 \mathrm{~Gb} / \mathrm{s} \text { demo [10] }\end{array}$ & $\begin{array}{l}\text { complex operation, } \\
\text { trailing pulses due to } \mathrm{AR}\end{array}$ \\
\hline ML-FRL & $\begin{array}{c}\mathrm{TF} \sim 1 \mathrm{ps}, \\
\text { tuneable } \lambda \text { in C-band } \\
640 \mathrm{~Gb} / \mathrm{s} \text { demo }[11]\end{array}$ & $\begin{array}{c}\text { complex architecture, } \\
\text { bulky } \\
\text { stability issues? }\end{array}$ \\
\hline EAM [12] & $\begin{array}{c}\text { T'F } \sim 4 \mathrm{ps}, \\
\text { simple, small, } \\
\text { tuneable beyond C-band }\end{array}$ & $\begin{array}{l}\text { high } \mathrm{V}_{p p} \text {, } \\
\text { limited to } 160 \mathrm{~Gb} / \mathrm{s} \text { ? }\end{array}$ \\
\hline
\end{tabular}

TABLE II

LIST OF MOST PROMISING COMMERCIALLY AVAILABLE PULSE SOURCES FOR HIGH BIT RATES. ERBiUM GLASS OSCILLATOR PULSE GENERATING LASER (ERGO-PGL), SEMICONDUCTOR TUNEABLE MODE-LOCKED LASER (TMLL), MODE-LOCKED FIBRE RING LASER (ML-FRL), ELECTROABSORPTION MODULATOR (EAM), AR: ANTI-REFLECTION COATING

within the last decade - some have reached a sufficient maturity and are now offered commercially. The most promising sources for ultra high bit rates, i.e. above $100 \mathrm{~Gb} / \mathrm{s}$ are listed in table II.

3) Timing jitter: Timing jitter is a serious detrimental factor in OTDM systems. The timing jitter of a pulse train must be very low to avoid random mixing of the time channels. For $160 \mathrm{~Gb} / \mathrm{s}$ data, the maximum allowed timing jitter on the data pulses is $400 \mathrm{fs}$, but for $640 \mathrm{~Gb} / \mathrm{s}$ data this requirement is four times lower, i.e. about 100 fs [13]. The ML-FRL and the ERGO PGL fulfil these strict requirements. The ML-FRL, though, being a physically extended component relying on locking of many longitudinal modes, has some long term stability issues. Recently, monolithically integrated modelocked semiconductor lasers with very low jitter have also been developed, e.g. as low as 80 fs jitter [14]. All of the mentioned pulse sources require further pulse compression for use at 640) $\mathrm{Gb} / \mathrm{s}$, see e.g. [5].

4) Dispersion requirements: Table III shows the tolerances to dispersion (D) and dispersion slope (S) in terms of how much residual $\mathrm{D}$ and $\mathrm{S}$ can be tolerated before a power penalty of $1 \mathrm{~dB}$ is suffered during transmission. The table also lists how many metres of standard single mode fibre (SMF) these values correspond to.

\begin{tabular}{|c|c|c|c|}
\hline & $D[\mathrm{ps} / \mathrm{nm}]$ & $\mathrm{S}\left[\mathrm{ps} / \mathrm{nm}^{2}\right]$ & SMF $[\mathrm{m}]$ \\
\hline $160 \mathrm{~Gb} / \mathrm{s}$ & 2 & 5 & 100 \\
\hline $640 \mathrm{~Gb} / \mathrm{s}$ & 0.13 & 0.07 & 7 \\
\hline
\end{tabular}

TABLE III

DISPERSION TOLERANCES AT 160 AND $640 \mathrm{~GB} / \mathrm{S}$

Dispersion compensating fibre (DCF) is widely used, but phase modulation has recently been introduced to provide for fine tuning of the dispersion compensation, e.g. compensation of third order dispersion [6], [15], and for pre-compensation [16], [17] or even post-compensation [18].

\section{CLOCK RECOVERY}

After transmitting the data, one will need to synchronise a gate to it before processing it. This is increasingly challenging at high bit rates, since an OTDM signal no longer contains a frequency component at the base rate, and so far locking to data rates above $160 \mathrm{~Gb} / \mathrm{s}$ has only been achieved by a few groups worldwide [19]-[21]. In all cases, phase-locked loops (PLL) using phase mixers with very high timing resolution were used. Table IV contains a short list of the current status on bit rate limits for various mixer types.

\begin{tabular}{|c|c|}
\hline mixer & bit rate \\
\hline electrical & $100 \mathrm{~Gb} / \mathrm{s} \mathrm{[22]}$ \\
\hline electro-optical, e.g. EAM & $\begin{array}{c}160 \mathrm{~Gb} / \mathrm{s}[23],[24] \\
(320 \mathrm{~Gb} / \mathrm{s} \mathrm{DPSK} \mathrm{[19])}\end{array}$ \\
\hline all-optical, e.g. FWM-SOA & $400 \mathrm{~Gb} / \mathrm{s} \mathrm{[20]}$ \\
\hline
\end{tabular}

TABLE IV

SUMMARY OF CURRENT BIT RATE LIMITS FOR VARIOUS MIXERS IN PLL-BASED CLOCK RECOVERY SCHEMES

An all-optical approach is the only alternative when going to very high bit rates (beyond $160 \mathrm{~Gb} / \mathrm{s}$ ). At these rates one can utilise extremely fast non-linear all-optical effects such as four wave mixing (FWM) or cross-phase modulation in SOAbased devices.

5) FWM-based clock recovery: Figure 2 shows the setup of a FWM-based clock recovery scheme for $160 \mathrm{~Gb} / \mathrm{s}$ operation.

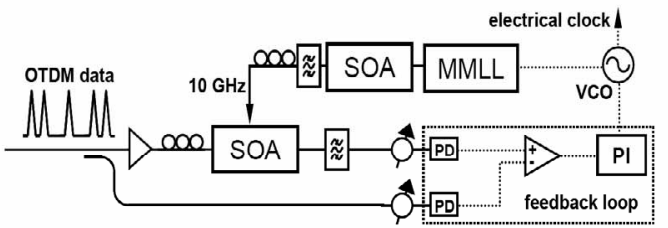

Fig. 2. FWM-based clock recovery set-up.

The set-up contains three active semiconductor components: a monolithic mode-locked laser (MMLL), an amplifying SOA and an SOA for FWM. All these active components are InGaAsP multiple quantum well (MQW) devices and may be integrated on one chip. The heart of the set-up is the phase comparator SOA (PC-SOA: $2 \mathrm{~mm}$ long, 8 quantum wells (QWs) for efficient FWM). Instead of an EDFA in the loop [20], a considerable improvement is found by shortening the loop using a booster SOA (2 mm long, 3 QWs ensuring high saturation output power). The MMLL is an all-active $2 \mathrm{QW}$ laser, ensuring narrow pulses (3.9 ps) and low timing jitter $\left(\tau_{\text {jitt }} \sim 80 \mathrm{fs}\right)$, running at $10 \mathrm{GHz}$ at $1560 \mathrm{~nm}$ [25]. The OTDM data is amplified, merged with the clock pulses and injected 

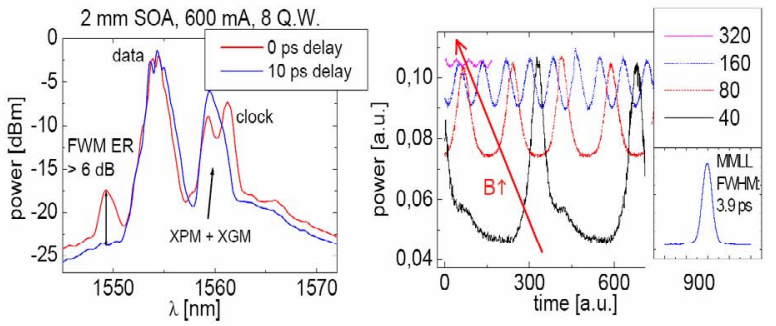

Fig. 3. FWM-based error signals. Left: spectrum with no control-data pulse overlap (10 ps delay) and with overlap ( 0 ps delay) resulting in FWM. Right: error signals at bit rates from $40-320 \mathrm{~Gb} / \mathrm{s}$.

into the PC-SOA to generate FWM. Filtering out the FWM wavelength yields an error signal proportional to the phase difference between the data and the clock pulses. The error signal is leveled to zero by balancing the two photodiodes (PD, $100 \mathrm{MHz}$ bandwidth), thus generating a bipolar signal. This is fed back, through a proportional integrator filter (PI), to a voltage controlled oscillator (VCO), which drives the MMLL.

Figure 3 shows the error signals produced with the FWMbased scheme. The timing resolution is determined by the clock pulse $(3.9 \mathrm{ps})$, which can clearly resolve the individual data pulses for bit rates from $40-160 \mathrm{~Gb} / \mathrm{s}$.

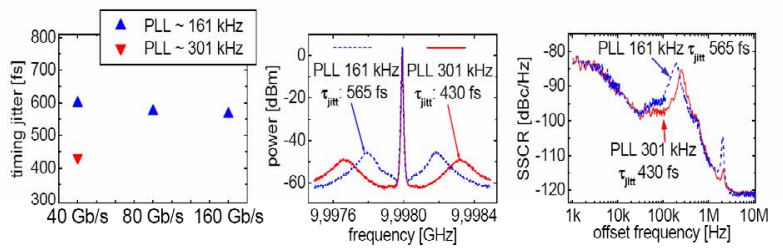

Fig. 4. FWM-based results. Left: Jitter of the recovered clock at various bit rates. Middle: microwave spectrum of recovered clock. Right: SSCR. Optimisation of the PLL-bandwidth reduces the sideband noise, thus lowering the jitter.

The locking performance is characterised by the timing jitter of the recovered clock, measured with the single sideband to carrier ratio (SSCR) method [26], and becomes about 600 fs. Figure 4 (left) summarises the measured jitter values at the various bit rates: the jitter is basically independent of the incoming bit rate, remaining just less than 600 fs for a PI bandwidth of $161 \mathrm{kHz}$. The loop length is $22 \mathrm{~m}$ due to various pigtails, corresponding to a delay of about $110 \mathrm{~ns}$. The PI-filter needs to be slower than the delay in order to actively track the data signal, and for a $110 \mathrm{~ns}$ delay the bandwidth must be less than $350 \mathrm{kHz}$ to obtain a lock, as theoretically predicted in [27]. Thus, lower timing jitter may be obtained by shortening the loop and increasing the bandwidth.

Figure 4 (middle and right) show the microwave spectrum and the SSCR measurements when the PI-bandwidth is experimentally optimised to the upper limit $301 \mathrm{kHz}$. The sideband phase noise peak at $190 \mathrm{kHz}$ is clearly suppressed and pushed out to $270 \mathrm{kHz}$, corresponding to a timing jitter reduction of more than $100 \mathrm{fs}$. The optimised jitter ( $430 \mathrm{fs}$ ) would be adequate for error free demultiplexing of the $160 \mathrm{~Gb} / \mathrm{s}$ data signal [13]. The jitter may be reduced further by shortening the loop [24] by integration of the compact semiconductor components.

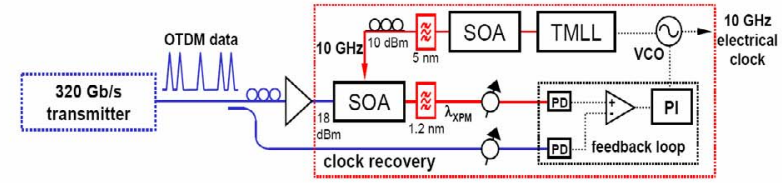

Fig. 5. Set-up for f-a XPM-based CR.

6) $320 \mathrm{~Gb} / \mathrm{s}$ Filtering-assisted XPM-based clock recovery: A pulsed control laser with narrower pulses is introduced and filtering-assisted cross-phase modulation ( $\mathrm{f}-\mathrm{a}$ XPM) in an SOA enables locking to $320 \mathrm{~Gb} / \mathrm{s}$. $\Lambda$ gain, all active components are semiconductor-based.

Figure 5 shows the set-up for locking to $320 \mathrm{~Gb} / \mathrm{s}$. The data signal, based on $1.3 \mathrm{ps}$ pulses at $1555 \mathrm{~nm}$, is amplified and spectrally filtered before injected into the clock recovery circuit together with the local SOA-boosted clock signal, a 10 $\mathrm{GHz}$ pulse train from a commercial semiconductor tuneable mode-locked laser (TMLL) driven by the VCO. The used SOAs are the same as in the FWM case. The TMLL is running at $1560 \mathrm{~nm}$ with a pulse width of $2.2 \mathrm{ps}$. Here, filtering-assisted cross-phase modulation of the clock pulses by the data pulses is used as mixing process. As the data pulses travel through the SOA, they give rise to changes in the carrier density due to ultra-fast carrier dynamics such as spectral hole burning (SHB) due to stimulated emission, carrier-carrier scattering (C-C) and carrier heating $(\mathrm{C}-\mathrm{H})$. This results in a phase modulation of the clock pulses, i.e. they get chirped. This chirp may be used to enhance the speed response of an SOA if a narrow filter is placed at the SOA output [28]. In this experiment, a $1.2 \mathrm{~nm}$ filter is centred on the red shifted side of the clock $\sim 1562 \mathrm{~nm}$. A phase modulation of the clock is thus transferred into an intensity modulation, which can be directly detected, generating an error signal.
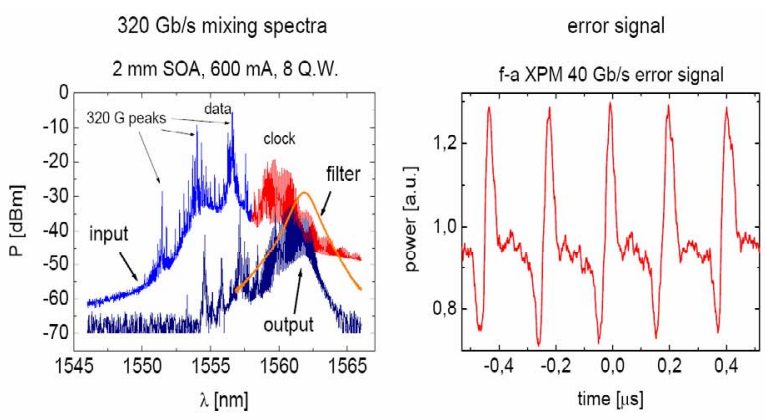

Fig. 6. Error signals by f-a XPM. Left: SOA input and filtered output spectra. Right: Generated emror signal for a $40 \mathrm{~Gb} / \mathrm{s}$ dala signal.

Figure 6 shows the input and filtered output spectra from the SOA together with a $40 \mathrm{~Gb} / \mathrm{s}$ error signal. The filter is tuned so that both an amplitude and phase change are allowed through, yielding a dispersion shaped 3-level curve [28].

Figure 7 shows error signals for 80,160 and $320 \mathrm{~Gb} / \mathrm{s}$ together with the locking results. In all cases, it is possible to obtain locking and with similar performance, again demonstrating that the speed limitation mostly stems from the mixer. The best locking performance obtained for this set-up 

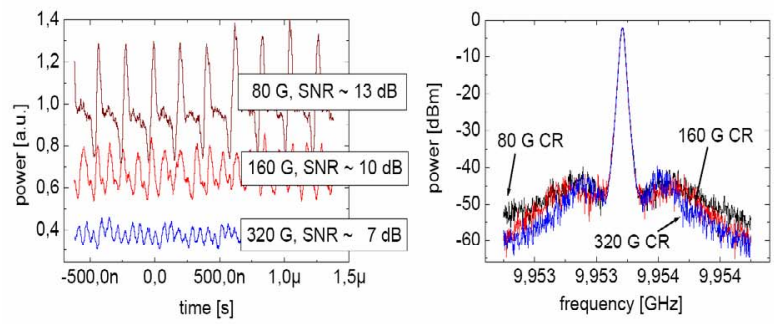

Fig. 7. Error signals by f-a XPM up to $320 \mathrm{~Gb} / \mathrm{s}$ (left) and microwave power spectra of the locked clock up to $320 \mathrm{~Gb} / \mathrm{s}$.

corresponds to a timing jitter of $800 \mathrm{fs}$, which is due to PLLnoise from the VCO, the TMLL (400 fs jitter on its own), the mixer, and the active components in the loop filter. This jitter value can be further reduced by minimising these noise sources and further reduce the length of the loop, and use narrower clock pulses.

\section{WAVELENGTH CONVERSION AND REGENERATION}

$160 \mathrm{~Gb} / \mathrm{s}$ regeneration [29] and wavelength conversion [30][36] have only been demonstrated by a few groups worldwide so far. In this section, a fibre-based Raman-assisted $160 \mathrm{~Gb} / \mathrm{s}$ (and above) regenerative wavelength converter is described.

7) $160 \mathrm{~Gb} / \mathrm{s}$ wavelength conversion and regeneration: A wavelength converter based on notch-filtered cross-phase modulation (XPM) assisted by Raman gain is shown in Figure 8 .

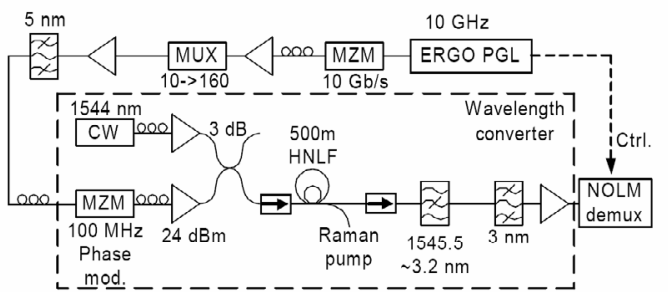

Fig. 8. Raman-assisted XPM regenerative wavelength converter.

The optical signal is generated by an ERGO-PGL at $10 \mathrm{GHz}$ and $1557 \mathrm{~nm}$. Data modulation and multiplexing to $160 \mathrm{~Gb} / \mathrm{s}$ are done as previously described with a multiplexer. Phase modulation is performed by a symmetrically driven MZM at $100 \mathrm{MHz}$ to suppress Stimulated Brillouin Scattering (SBS) from the narrow spectral components of the multiplexed high speed signal [37]. The signal is amplified by an EDFA to $24 \mathrm{dBm}$ and combined with a $14.6 \mathrm{dBm} \mathrm{CW}$ at $1544 \mathrm{~nm}$ and $\sim 500 \mathrm{MHz}$ line-width before injection into $500 \mathrm{~m}$ of highly non-linear fibre (HNLF), with a zero dispersion at $1551 \mathrm{~nm}$, a dispersion slope of $0.017 \mathrm{ps} / \mathrm{nm}^{2} \mathrm{~km}$, and a nonlinear coefficient $\gamma \sim 10.5 \mathrm{~W}^{-1} \mathrm{~km}^{-1}$. In the HNLF a counterpropagating $200 \mathrm{~mW}$ Raman pump enhances the XPM process and provides amplification of the signal. The data generates sidebands on the CW carrier through XPM mediated by the Kerr effect in the HNLF. As sidebands on either side of the carrier are out of phase it is imperative to select only one sideband [33]. This is done using a custom made Fibre Bragg Grating (FBG) as a notch filter to suppress the $\mathrm{CW}$ and one
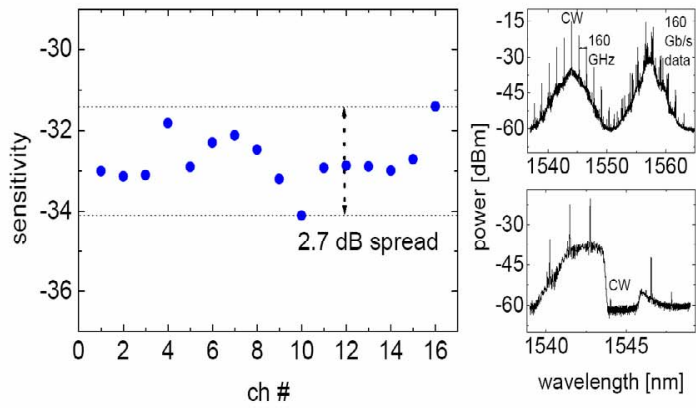

Fig. 9. Raman-assisted XPM regenerative wavelength conversion. Left: receiver sensitivities of all converted and demultiplexed channels. Right: output spectrum of HNLF (top) and after notch and band pass filtering (bottom).

XPM sideband and a band pass filter to suppress the original data signal. The FBG has its centre wavelength at $1545.5 \mathrm{~nm}$ and a bandwidth of $3.2 \mathrm{~nm}$. The wavelength converted signal is demultiplexed in a non-linear optical loop mirror (NOLM) to the $10 \mathrm{~Gb} / \mathrm{s}$ base rate using $2 \mathrm{ps}$ control pulses from the 10 $\mathrm{GHz} 1557 \mathrm{~nm}$ pulse source.

BER measurements are performed to evaluate the system performance and the receiver sensitivity (BER 1E-9) results for all channels are shown in figure 9. Figure 9 (top, right) shows the data signal spectrum and the XPM broadening of the CW spectrum recorded at the output of the HNLF before filtering. Strong $160 \mathrm{GHz}$ modulation peaks can be seen in the XPM broadened spectrum indicating a significant stabilisation of the phase in the converted signal compared to the input signal, owing to the high coherence of the CW source [38]. Figure 9 (bottom, right) shows the spectrum of the converted signal after filtering. The $\mathrm{CW}$ and part of the red sideband are suppressed $>40 \mathrm{~dB}$ and the strong $160 \mathrm{GHz}$ spectral components are retained after filtering.

All channels are error free with an average sensitivity of -33 $\mathrm{dBm}$ with a variation of $2.7 \mathrm{~dB}$, resulting in an average penalty of $0.4 \mathrm{~dB}$ compared to the $10 \mathrm{~Gb} / \mathrm{s}$ back-to-back. The $2.7 \mathrm{~dB}$ spread is due to amplitude variations in the multiplexed signal. The fact that one channel is clearly better than the original 10 $\mathrm{Gb} / \mathrm{s}$ signal indicates that there are regenerative properties of the process, and indeed the zero level in the converted signal is generally suppressed with respect to the incoming signal [34].

8) $160 \mathrm{~Gb} / \mathrm{s}$ transmission and in-line wavelength conversion: The Raman-assisted wavelength converter is placed in an in line transmission link to verify its transmission capability [36]. The set-up used is depicted in figure 10. In this particular set-up, a $10 \mathrm{GHz}$ pulsed clock signal is transmitted with the data signal but in orthogonal polarisation. Thus the clock and data can be on the same wavelength - this reduces the amount of needed pulsed laser sources to one.

After transmission through $80 \mathrm{~km}$ SMF and appropriate DCF for GVD/slope compensation, the signal is converted to $1543 \mathrm{~nm}$, and subsequently transmitted through a $50 \mathrm{~km}$ span of SMF-IDF, before being demultiplexed in a NOLM using the $10 \mathrm{GHz}$ transmitted clock pulses as control.

Figure 11 (left) shows the receiver sensitivities of all 16 


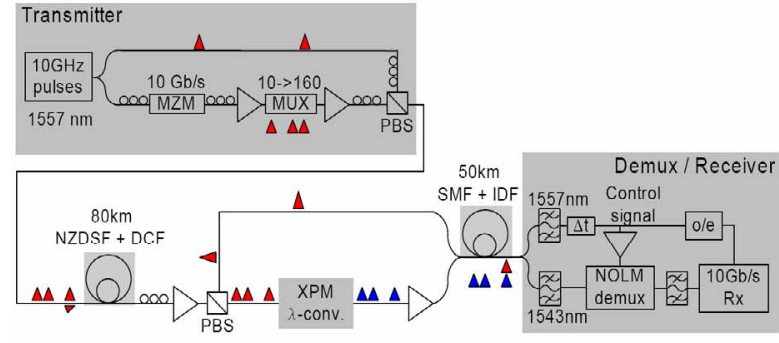

Fig. 10. In-line $160 \mathrm{~Gb} / \mathrm{s}$ wavelength conversion set-up.

demultiplexed converted data channels after the first $80 \mathrm{~km}$ transmission span. All channels are error free with a spread of about $3 \mathrm{~dB}$ in sensitivity. The channels closest to the transmitted clock pulse suffer from a slightly larger penalty due to incomplete polarisation extinction. Figure 11 (right) shows an oscilloscope trace of the detected clock signal (in a $14 \mathrm{GHz}$ detector, which broadens the pulse to a sine), and the $160 \mathrm{~Gb} / \mathrm{s}$ eye detected on a $50 \mathrm{GHz}$ detector and a $70 \mathrm{GHz}$ scope, which indicates a clear $160 \mathrm{~Gb} / \mathrm{s}$ structure. The clock signal is a clear well-defined trace with low timing jitter $(\sim$ $300 \mathrm{fs}$ ), sufficient for stable demultiplexing.

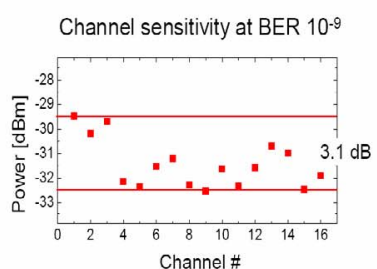

Channel \#

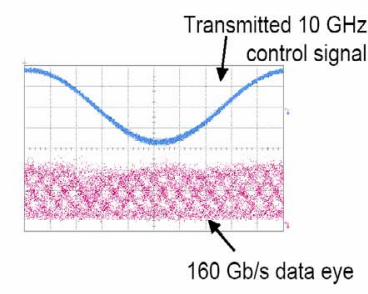

Fig. 11. $80 \mathrm{~km}$ SMF followed by $160 \mathrm{~Gb} / \mathrm{s}$ wavelength conversion. Left: Sensitivities of all 16 demultiplexed channels. Right: Transmitted detected clock signal and 160) Gb/s converted eye (on 70) GHz scope).

Figure 12 (left) shows the results for all 16 channels in terms of receiver sensitivities after the full $130 \mathrm{~km}$ transmission and conversion. All 16 channels show good performance, however, after the final transmission stage the channel coinciding with the clock pulse is influenced by the clock pulse too much to get error free performance (1.1E-8 BER obtained). Again, this is because of the incomplete polarisation extinction in the first span, which is accumulated through the last span. The remaining 15 channels are all error free with a sensitivity spread of about $4.5 \mathrm{~dB}$. Also shown are the results for the case when no Raman pump is used, which increases the penalty with $0.8 \mathrm{~dB}$.

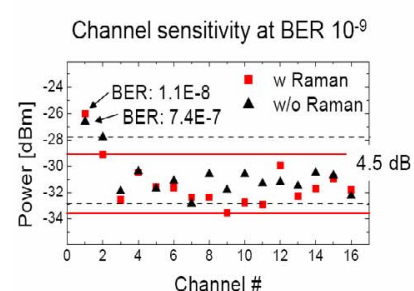

$160 \mathrm{~Gb} / \mathrm{s}$ data eye and control signal

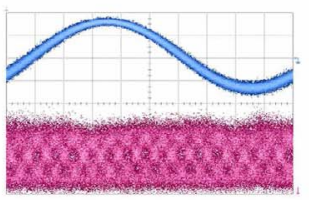

Fig. 12. In-line $160 \mathrm{~Gb} / \mathrm{s}$ wavelength conversion after full $130 \mathrm{~km}$ transmission. Left: Sensitivities of all 16 demultiplexed channels. Right: Transmitted detected clock signal and $160 \mathrm{~Gb} / \mathrm{s}$ converted eye (on $70 \mathrm{GHz}$ scope).
Figure 12 (right) shows the detected clock signal and additional timing jitter is observed on the clock ( $\sim 450 \mathrm{fs}$ ). So, the clock signal has clearly deteriorated through the last span, but the majority of channels still retain an average sensitivity of about $-32 \mathrm{dBm}$, as before the last span. It is only the channel overlapping with the clock that is completely distorted, so there may be some spectral mixing between the clock pulse and the coinciding data pulse.

To summarise, this final section has shown that the wavelength conversion concept described here relying on Ramanassisted cross-phase modulation truly works in a real transmission link. Furthermore, it should be mentioned that this technique is scalable to higher bit rates, and it has recently been demonstrated at $320 \mathrm{~Gb} / \mathrm{s}$ [39].

\section{CONCLUSION}

This paper has described some recent advances within the fields of ultra-fast clock recovery and all-optical wavelength conversion. We have described how various laboratory solutions for clock recovery for operation at $160 \mathrm{~Gb} / \mathrm{s}$ and $320 \mathrm{~Gb} / \mathrm{s}$ have been developed and experimentally verified, relying only on compact semiconductor components. It was found that filtering-assisted cross-phase modulation could be used as an ultra-fast all-optical mixer in a PLL-based clock recovery scheme operating up to $320 \mathrm{~Gb} / \mathrm{s}$. The fact that the whole circuit was based on compact semiconductor devices, indicates that this may be a viable solution for future monolithic integration into a single cheap component with a small footprint. We furthermore showed results on $160 \mathrm{~Gb} / \mathrm{s}$ wavelength conversion utilising benefits of Raman gain in non-linear fibres. The scheme was tested in a back-to-back situation as well as in a transmission link showing error free performance.

All in all, we have demonstrated that there are solutions for chosen key functionalities pertaining to high speed operation of optical networks, reaching 160 and $320 \mathrm{~Gb} / \mathrm{s}$. There are many impressive results in the literature, and with the ones mentioned here, the future of high speed communications looks bright.

\section{ACKNOWLEDGMENTS}

The work presented here is carried out within the Danish Research Council funded project Ultra-Net. OFS Fitel Denmark and Intel Copenhagen are acknowledged for providing selected equipment.

\section{REFERENCES}

[1] K. Murata, K. Sano, H. Kitabayashi, S. Sugitani, H. Sugahara and T. Enoki, "100 Gbit/s logic using IC using $100 \mathrm{~nm}$ gate length InAlAs/InGaAs/InP HEMTs," in Proc. IEEE International Electron Devices Meeting (2002).

[2] T. Yamamoto, E. Yoshida and M. Nakazawa, "Ultrafast nonlinear optical loop mirror for demultiplexing $640 \mathrm{Gitb} / \mathrm{s}$ TDM signals," Electron. Lett., vol. 34, no. 10, pp. 1013-1014, 1998.

[3] S. Watanabe, R. Okabe, F. Futami, R. Hainberger, C. Schmidt-Langhorst, C. Schubert and H.G. Weber, "Novel Fiber Kerr-Switch with Parametric Gain: Demonstration of Optical Demultiplexing and Sampling up to 640 Gb/s, postdeadline paper Th4.1.6," in Proc. European Conference on Optical Communication, ECOC (2004). 
[4] A.I. Siahlo, A.T. Clausen, L.K. Oxenløwe, J. Seoane and P. Jeppesen, "640 Gb/s OTDM transmission and demultiplexing using a NOLM with commercially available highly non-linear fiber, paper CTuO1," in Proc. IEEE Conference on Lasers and Electro-Optics, CLEO (2005).

[5] L.K. Oxenløwe, K.S. Berg, A.T. Clausen, J. Seoane, A.I. Siahlo, P. Jeppesen, M. Scmhidt, M. Schilling and Q. Le, "Specialty fibers for 16(), 320 and 640 Gb/s signal processing, paper CTHQ1," in Proc. IEEE Conference on Lasers and Electro-Optics, CLEO (2004).

[6] M. Nakazawa , T. Yamamoto and K.R. Tamura, "1.28 Tbit/s-70km OTDM transmission using third- and fourth-order simultaneous dispersion compensation with a phase modulator," Electron. Lett., vol. 36, no. 24, pp. 2027-2029, 2000.

[7] H.G. Weber, S. Ferber, M. Kroh, C. Schmidt-Langhorst, R. Ludwig, V. Marembert, C. Boerner, F. Futami, S. Watanabe and C. Schubert, "Single channel $1.28 \mathrm{Tbit} / \mathrm{s}$ and $2.56 \mathrm{Tbit} / \mathrm{s}$ DQPSK transmission," Electron. Lett., vol. 42, no. 3, 2006.

[8] A.T. Clausen, H.N. Poulsen, L.K. Oxenløwe, A.I. Siahlo, J. Seoane, and P. Jeppesen, "Pulse source requirements for OTDM systems, paper TuY2," in Proc. IEEE Lasers and Electro-Optics Society, LEOS (2003).

[9] J. Seoane, A.I. Siahlo, A.T. Clausen, L.K. Oxenløwe, P. Jeppesen, M Schmidt, M. Schilling and E. Lach, "Ultra high-speed demultiplexing using a NOLM based on commercially available highly non-linear fibre, paper We1.5.4," in Proc. European Conference on Optical Communications ECOC(2004).

[10] M. Kroh, C.M Weinert, C. Schmidt-Langhorst, C. Schubert, J. Berger, C. Börner, R. Ludwig and H.G. Weber, "Semiconductor mode-locked laser pulse source for 320 and $640 \mathrm{~Gb} / \mathrm{s}$ RZ data transmitter, paper We3.5.7," in Proc. European Conference on Optical Communications $\operatorname{ECOC}(2004)$.

[11] M. Nakazawa, E. Yoshida, Yamamoto, E. Yamada and A. Sahara, "TDM single channel $640 \mathrm{Gbit} / \mathrm{s}$ transmission experiment over $60 \mathrm{~km}$ using 400 fs pulse train and walk-off free, dispersion flattened nonlinear optical loop mirror," Electron. Lett., vol. 34, no. 9, 1998.

[12] E. Lach, M. Schmidt, M. Witte, K. Schuh, H. Buelow, F. Buchali, A.T Clausen. L.K. Oxenløwe, B. Sartorius, C. Kazmierski, S. Vorbeck, R. Leppla, E. Le-Rouzic, B. Cuenot, A. Richter, F. Ramos, R. Llorent, G. Charlet, P. Pecci and D. Rouvillain, "DWDM transmission at ultra-high channel bitrates: European TOPRATE project view, Symposium paper Tul.1.2," in Proc. European Conference on Optical Communications ECOC(2004).

[13] M. Jinno, "Effects of Crosstalk and Timing Jitter on All-Optical TimeDivision Demultiplexing Using a Nonlinear Fiber Sagnac Interferometer Switch," J. Quantum Electron., vol. 30, no. 12, 1994.

[14] K. Yvind, D. Larsson, L.J. Christiansen, C. Angelo, L.K. Oxenløwe, J. Mørk, D. Birkedal, J.M. Hvam and J. Hanberg, "Low-Jitter and HighPower 40-GHz All-Active Mode-Locked Lasers," Photon. Technol. Lett., vol. 16, no. 4, pp. 975-977, 2004.

[15] M. Nakazawa, T. Hrooka, F. Futami and S. Watanabe, "Ideal distortionfree transmission using optical Fourier transformation and transformlimited ultrashort pulses, postdeadline paper Th4.3.8," in Proc. European Conference on Optical Communication, ECOC (2003).

[16] A.I. Siahlo, L.K. Oxenløwe, J. Seoane, K.S. Berg, A.T. Clausen and P. Jeppesen, "tuneable pre-compensation, paper We4.P.105," in Proc European Conference on Optical Communication, ECOC (2003).

[17] I. Shake, H. Takara and S. Kawanishi, "Large-dispersion-tolerance picosecond optical pulse transmission using frequency chirp control, paper Mo4.2.3," in Proc. European Conference on Optical Communication, ECOC (2003)

[18] A.I. Siahlo, A.T. Clausen, L.K. Oxenløwe, J. Seoane, K.S. Berg, Z. Xu, J. Zeng and P. Jeppesen, "Phase Modulation for Postcompensation of dispersion in $160 \mathrm{~Gb} / \mathrm{s}$ Systems," Photon. Technol. Lett., vol. 17, no. 2. pp. 498-500, 2005.

[19] V. Marembert, C. Schubert, S. Ferber, K. Schulze, C. SchmidtLanghorst, C. Boerner, M. Kroh, R. Ludwig, S. Watanabe, F. Futami, R. Okabe and H.G. Weber, "Single-channel $640 \mathrm{~Gb} / \mathrm{s}$ DPSK Transmission over a $160 \mathrm{~km}$ Fibre Link, postdeadline paper Th4.4.2," in Proc. European Conference on Optical Communication, ECOC (2004).

[20] O. Kamatami and S. Kawanishi, "Prescaled Timing Extraction from 400 $\mathrm{Gb} / \mathrm{s}$ Optical Signal Using a Phase Lock Loop Based on Four-WaveMixing in a Laser Diode Amplifier," Photon. Technol. Lett., vol. 8, no. 8, 1996

[21] L.K. Oxenløwe, D. Zibar, M. Galili, A.T. Clausen, L.J. Christiansen and P. Jeppesen, "Filtering-assisted cross-phase modulation in a semiconductor optical amplifier enabling $320 \mathrm{~Gb} / \mathrm{s}$ clock recovery, paper We3.5.5," in Proc. European Conference on Optical Communication, ECOC (2005).
[22] Phillips, I.D., Ellis, A.D. Widdowson, T. and Nesset, D. and Kelly, A.E and Trommer, D., "100 Gbit/s optical clock recovery using electrical phaselocked loop consisting of commercially available components," Electron. Lett., vol. 36, no. 7, 2000 .

[23] C. Boerner, C. Schubert, C. Schmidt, E. Hilliger, V. Marembert, J. Berger, S. Ferber, E. Dietrich, R. Ludwig, B. Schmauss and H.G. Weber, "160 Gbit/s clock recovery with electrooptical PLL using bidirectionally operated electroabsorption modulator as phase comparator," Electron. Lett., vol. 39, no. 14, pp. 1071-1073, 2003.

[24] L.K. Oxenløwe, A.I. Siahlo, K.S. Berg, A.T. Clausen, B.M. Sørensen, K. Yvind, P. Jeppesen, K.P. Hansen, K. Hoppe and J. Hanberg, "A novel $160 \mathrm{~Gb} / \mathrm{s}$ receiver configuration including a glass crystal pulse laser, hotonic crystal fibre and a simple dynamic clock recovery scheme, paper Th2.5.3," in Proc. European Conference on Optical Communication, ECOC (2003).

[25] D. Larsson, K. Yvind, L.J. Christiansen, J. Mørk, J. Hvam and J. Hanberg, "Novel design of low-jitter $10 \mathrm{GHz}$ all-active monolithic modelocked lasers, paper CFC4," in Proc. (IEEE) Conference on Lasers and Electro-Optics, CLEO (2004).

[26] D. von der Linde, Appl. Phys. B, vol. 39, no. 201, 1986.

[27] D. Zibar, J. Mørk, L.K. Oxenlo\}we, M. Galili and A.T. Clausen, "Timing Jitter Analysis for Clock Recovery Circuits Based on an Optoelectronic Phase-Locked Loop (OPLL), paper CMZ4," in Proc. (IEEE) Conference on Lasers and Electro-Optics, CLEO (2005).

[28] M.L. Nielsen, B. Lavigne and B. Dagens, "Polarity-preserving SOAbased wavelength conversion at $40 \mathrm{Gbit} / \mathrm{s}$ using bandpass filtering," Electron. Lett., vol. 39, no. 18, pp. 1334-1335, 2003.

[29] S. Watanabe, R. Ludwig, F. Futami, C. Schubert, S. Ferber, C. Boerner, C. Schmidt-Langhorst, J. Berger and H.-G. Weber, "Ultrafast all-optical 3R-regeneration," IEICE Transactions on Electronics, vol. Vol.E87-C, no. 7, pp. 1114-1118, 2004

[30] S. Nakamura, Y. Ueno and K. Tajima, "168-Gb/s all-optical wavelength conversion with a symmetric-Mach-Zehnder-type switch," Photon. Technol. Lett., vol. 13, no. 10, pp. 1091-1093, 2001.

[31] W. Wang, H.N. Poulsen, L. Rau, H.-E. Chou,, J.E. Bowers, D.J. Blumenthal and L. Gruner-Nielsen, "Regenerative 80-Gb/s Fiber XPM Wavelength Converter Using a Hybrid Raman/EDFA Gain-Enhanced Configuration," Photon. Technol. Lett., vol. 15, no. 10, pp. 1416-1418, 2003.

[32] M. Galili, L.K. Oxenløwe, D. Zibar, A.T. Clausen and P. Jeppesen, "160 $\mathrm{Gb} / \mathrm{s}$ Raman-assisted SPM wavelength converter, postdeadline paper Th4.3.1," in Proc. European Conference on Optical Communication, ECOC (2004)

[33] M. Galili, L.K. Oxenløwe, D. Zibar, A.T. Clausen, P. Jeppesen, H.-J. Deyerl, N. Plougmann, M. Kristensen, "Characterisation of Systems for Raman-Assisted High-Speed Wavelength Conversion, paper CMQ2," in Proc. (IEEE) Conference on Lasers and Electro-Optics, CLEO (2005).

[34] M. Galili, L.K. Oxenløwe, D. Zibar, A.T. Clausen, H.J. Deyerl, N. Plougmann, M. Kristensen and P. Jeppesen, "160 Gb/s notch-filtered Raman-assisted XPM wavelength converter, paper Mo4.5.3," in Proc. European Conference on Optical Communication, ECOC (2005).

[35] Y. Liu, E. Tangdiongga, Z. Li, H. de Waardt, A.M.J. Koonen, G.D. Khoe, H.J.S. Dorren, X. Shu and I. Bennion, "Error-free $320 \mathrm{~Gb} / \mathrm{s}$ SOA-based wavelength conversion using optical filtering, paper PDP28," in Proc. IEEE Conference on Lasers and Electro-Optics, OFC (2006).

[36] M. Galili, L.K. Oxenløwe, H.C.H. Mulvad, D. Zibar, A.T. Clausen and P. Jeppesen, "160 Gb/s Raman-assisted notch-filtered XPM wavelength conversion and transmission, paper OWW2," in Proc. IEEE Conference on Lasers and Electro-Optics, OFC (2006).

[37] D. Dahan, A. Bilenca and G. Eisenstein, "Noise-reduction capabilities of a Raman-mediated wavelength converter," Optics Lett., vol. 28, p. $634,2003$.

[38] L. Rau, W. Wang, S. Camatel, H. Poulsen and D.J. Blumenthal, "Alloptical $160-\mathrm{Gb} / \mathrm{s}$ phase reconstructing wavelength conversion using cross-phase modulation (XPM) in dispersion-shifted fiber," Photon. Technol. Lett., vol. 16, no. 11, pp. 2520-2522, 2004.

[39] M. Galili et al, "320 Gb/s Raman-assisted XPM wavelength conversion," to be published elsewhere. 